P0177

\title{
STUDY ON IMPROVEMENT OF LOW POSITION ROAD LIGHTING INSTALLATIONS IN A POOR VISUAL RANGE \\ Yoshinori Karasawa et al.
}

DOI 10.25039/x46.2019.PO177

from

CIE x046:2019

Proceedings

of the

29th CIE SESSION

Washington D.C., USA, June 14 - 22, 2019

(DOI 10.25039/x46.2019)

The paper has been presented at the 29th CIE Session, Washington D.C., USA, June 14-22, 2019. It has not been peer-reviewed by CIE.

(C) CIE 2019

All rights reserved. Unless otherwise specified, no part of this publication may be reproduced or utilized in any form or by any means, electronic or mechanical, including photocopying and microfilm, without permission in writing from CIE Central Bureau at the address below. Any mention of organizations or products does not imply endorsement by the CIE.

This paper is made available open access for individual use. However, in all other cases all rights are reserved unless explicit permission is sought from and given by the CIE.

CIE Central Bureau

Babenbergerstrasse 9

A-1010 Vienna

Austria

Tel.: +4317143187

e-mail: ciecb@cie.co.at

www.cie.co.at 


\title{
STUDY ON IMPROVEMENT OF LOW POSITION ROAD LIGHTING INSTALLATIONS IN A POOR VISUAL RANGE
}

\author{
Yoshinori Karasawa ${ }^{1}$, Hiroo Wada ${ }^{2}$ \\ ${ }^{1}$ Panasonic Corp., OSAKA, JAPAN, ${ }^{2}$ Central Nippon Expressway Co. Ltd., Tokyo, JAPAN \\ karasawa.yoshinori@jp.panasonic.com
}

DOI 10.25039/x46.2019.PO177

\begin{abstract}
Low position road lighting installations are effective to prevent collapse and drop of ancillary road facilities in the event of accidents and disasters, provide ease of inspection and produce less light pollution. From these factors, they have become a mainstream of road lighting system taking the place of lighting poles. This paper reports the advantages of Low position road lighting installations demonstrated by operational experiments in a poor visual range.
\end{abstract}

Keywords: low position road lighting, roadside lighting, poor visual rage, glare,

\section{Key considerations}

In a poor visual range such as in dense fog or heavy rain, irradiation from road lighting installations may produce veiling effects, resulting in a further decline in visibility. Low position road lighting installations that are mounted on a lower position emit considerably less light in space, namely producing less veiling effects as compared with lighting poles. In addition, a shorter distance between each lighting installation provides ease of recognition of road alignments. Strengthening these advantages of Low position road lighting installations may contribute to enhanced driving safety at high speed.

With this in view, this paper conducted operational experiments with the aim of finding the best combination of color temperature and luminous intensity distribution in a poor visual range.

\section{Experiments and results}

\subsection{Steps of experiments}

(1) Preliminary experiment 1 Period: February 28, 2018, Place: National Traffic Safety and Environment Laboratory (Law Visibility Test room)

(2) Preliminary experiment 2 Period: June 5, 2018, Place: Chuo Expressway, up-line (on an obsolete road near Dangozaka Service Area)

(3) Experiment Period: August 7-9, Place: Japan Automobile Research Institute (Specific Environment Laboratory)

\subsection{Details of experiments}

(1) Preliminary experiment 1

[Objective] Evaluation of the visibility of the preceding vehicle, white line in different color temperatures in a poor visual range.

[Equipment] Low position road lighting installations: 3 units (at a distance of $6 \mathrm{~m}$ respectively), upward luminous flux: $2.6 \%$

[Conditions]

- Environmental conditions: Visual range in fog: $10 \mathrm{~m}$

- Color temperature: 5000 K, 4000 K, 3000K 
- Lighting conditions: Ordinary lighting and roadside lighting (see Figure 1,2)

[Measurement items] Horizontal illuminance, vertical illuminance, veiling luminance and visual range

[Evaluation method] Subjective evaluation of color temperature and glare of lighting installations at a standstill (10 lighting engineers)

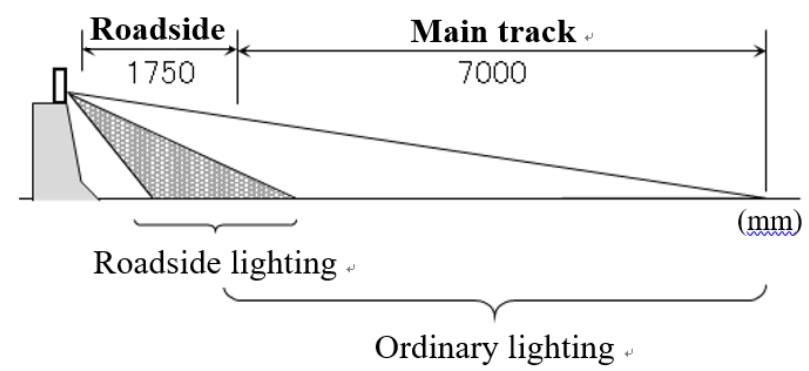

\section{Figure 1 - Cross-sectional view of two different lighting conditions (Ordinary lighting and Roadside lighting)}

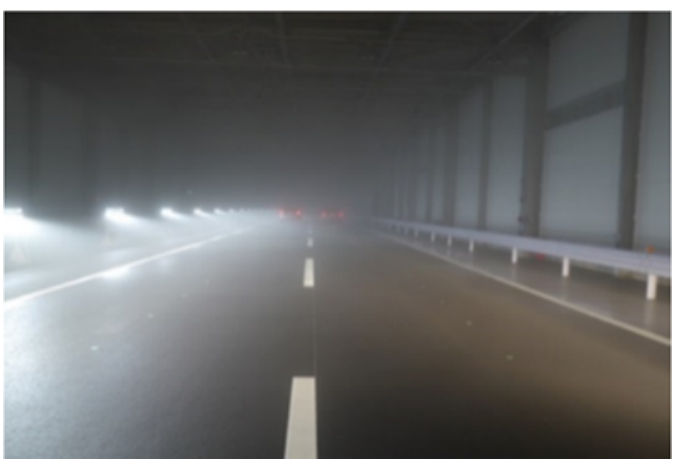

Figure 2 (1) - Ordinary lighting (visual range: $50 \mathrm{~m}$ )

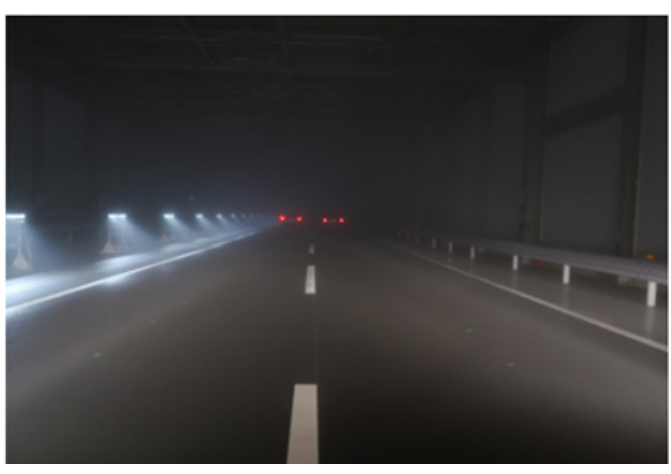

Figure 2 (2) - Roadside lighting (visual range: $100 \mathrm{~m}$ )

(2) Preliminary experiment 2

[Objective] Verify glare and flickering on actual roads in normal visual range.

[Equipment] Low position road lighting installations: 10 units (at a distance of $6 \mathrm{~m}$ respectively), upward luminous flux: $2.6 \%$

[Conditions]

- Environmental conditions: Nighttime

- Color temperature: $5000 \mathrm{~K}$

- Lighting conditions: Ordinary lighting and roadside lighting (see Figure 1,2)

[Measurement items] Horizontal illuminance and vertical illuminance

[Evaluation method] Subjective evaluation of glare and flickering under driving conditions (10 lighting engineers)

(3) Experiment

[Objective] Evaluate effective lighting conditions in a poor visual range

[Equipment] Low position road lighting installations: 17 units (at a distance of $6 \mathrm{~m}$ respectively in a lighting section of $96 \mathrm{~m}$ ), upward luminous flux: $1.2 \%$ 


\section{[Conditions] As shown in Table 1}

[Evaluation method] Subjective evaluation of visibility of preceding vehicle, recognition of road alignments and flickering from lighting installations in a visual range of $50 \mathrm{~m} / 100 \mathrm{~m}$ (10 lighting engineers)

Table 1 - Experiment evaluation conditions

\begin{tabular}{|c|c|c|c|c|}
\hline & & veather conditions & lighting system & luminance,Illuminance \\
\hline \multirow{4}{*}{ 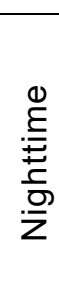 } & \multirow{2}{*}{ 안 } & $\begin{array}{l}\text { Visual range of } 50 \mathrm{~m} \\
\text { Visual range of } 100 \mathrm{~m}\end{array}$ & Ordinary & $1,0 / 0,5 \mathrm{~cd} / \mathrm{m}^{2}$ \\
\hline & & $\begin{array}{l}\text { Visual range of } 50 \mathrm{~m} \\
\text { Visual range of } 100 \mathrm{~m}\end{array}$ & Roadside & $25 / 601 x$ \\
\hline & \multirow{2}{*}{$\begin{array}{l}\stackrel{\complement}{\mathbb{T}} \\
\widetilde{\pi}\end{array}$} & \multirow{2}{*}{$30 \mathrm{~mm} / \mathrm{h}$} & Ordinary & $1,0 / 0,5 \mathrm{~cd} / \mathrm{m}^{2}$ \\
\hline & & & Roadside & $25 / 601 x$ \\
\hline
\end{tabular}

\subsection{Results of evaluation}

(1) Preliminary experiment 1

No differences were observed in visibility (preceding vehicle, white line) in a poor visual range between color temperatures.

It was verified that roadside lighting had a capability of reducing veiling effects significantly as compared with ordinary lighting and of improving visibility of a tail lamp of preceding vehicle and roadside white lines.

(2) Preliminary experiment 2

It was found that adverse effects on visual appearance of the driver were caused by trespass of a small amount of light into the vehicle from lighting installations (with upward luminous flux ratio of approx. $2.6 \%$ ) that had no glare issues in standstill experiment.

(3) Experiment

1) Nighttime fog

a) Visibility of preceding vehicle

In subjective evaluation, ordinary lighting $\left(1,0 \mathrm{~cd} / \mathrm{m}^{2}\right)$ had slightly better results in a visual range of $50 \mathrm{~m}$. In a visual range of $100 \mathrm{~m}$, however, there were no significant differences between the two types of lighting installations (Figure $3(1)$ and (2)).

From the evaluation opinions, the roadside lighting $(60 \mathrm{~lx})$ got favorable feedback such as "affording high visibility of a tail lamp of preceding vehicle".

b) Recognition of road alignments

In subjective evaluation, the luminaires on the roadside lighting installations provided a longer visible distance approximately by $20 \%$ than others in the visual range of $50 \mathrm{~m}$ (Figure 4).

From the evaluation opinions, the roadside lighting $(60 \mathrm{~lx})$ got favorable feedback such as "making a roadside clearly visible" and "affording high visibility of white lines."

c) Glare

In subjective evaluation, all luminous intensity distributions produced "almost no annoying glare" (Figure 5). From the evaluation opinions, the roadside lighting was advantageous in reducing glare. But, even on the ordinary lighting installations, the luminaires with strictly restricted upward luminous flux produced favorable results.

2) Nighttime rain

In subjective evaluation, Ordinary lighting is slightly better than roadside lighting for the appearance of the preceding car (Figure 6). But, water splashes by driving vehicles and veiling effects could not be replicated. In a video taken on an actual road after the subjective experiment, strong veiling effects were caused by water splashes in rainfall of $20 \mathrm{~mm}$ per hour (Figure 7). 


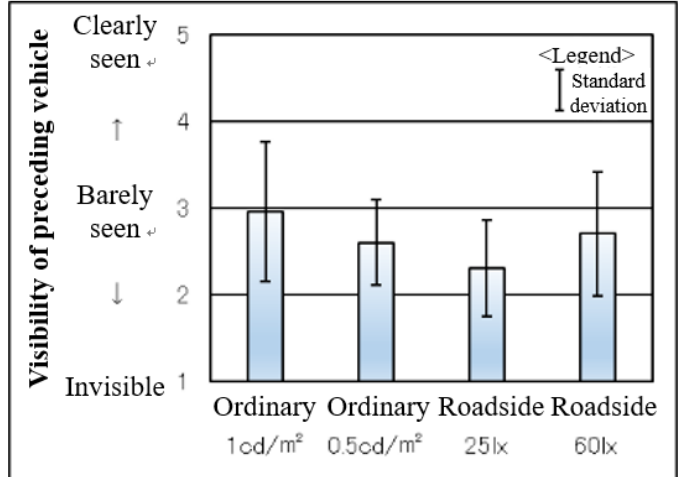

Figure 3 (1) - Visibility of preceding vehicle (visual range: 50 mi

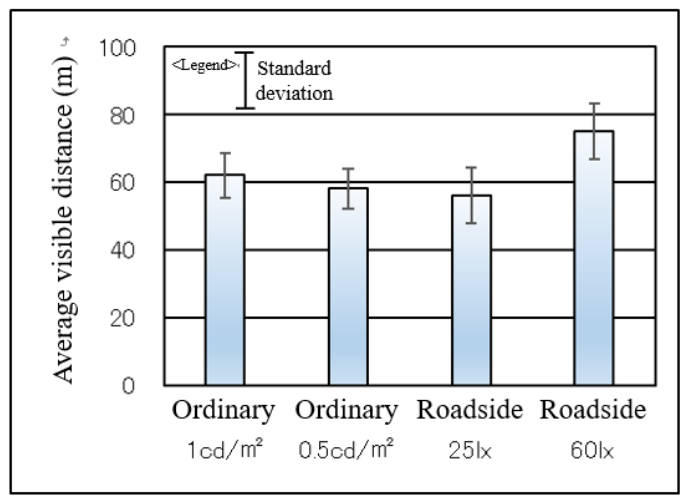

Figure 4 - Recognition of road alignments(visual range of $50 \mathrm{~m}$ )

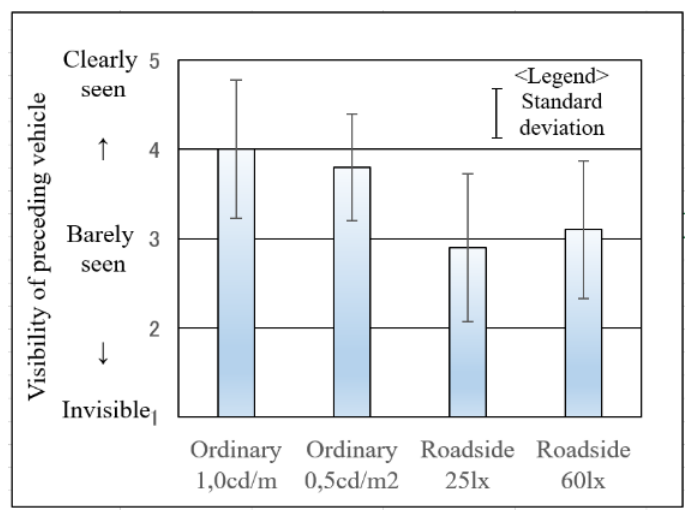

Figure 6 - Visibility of preceding vehicle (in rainfall of $30 \mathrm{~mm} / \mathrm{h}$ )

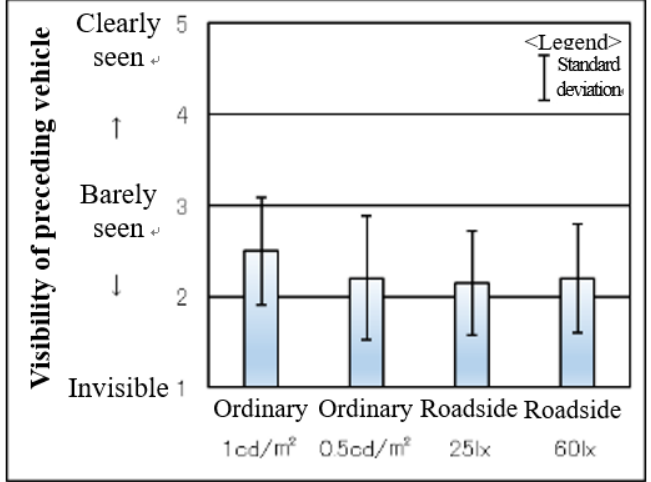

Figure $3(2)$ - Visibility of preceding vehicle (visual range: $100 \mathrm{~m}$ )

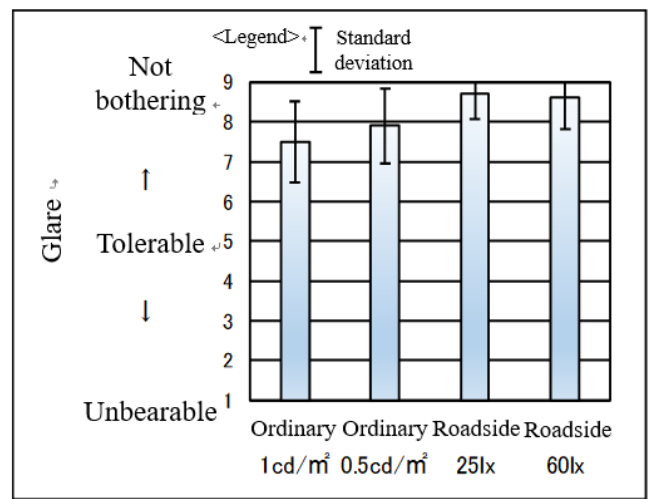

Figure 5 - Glare (visual range of $50 \mathrm{~m}$ )

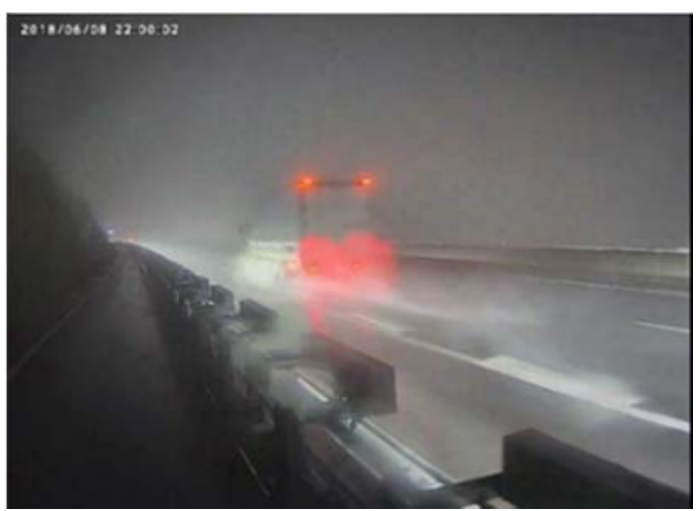

Figure 7 - Water splashes by a driving vehicle in actual road

\section{Conclusion}

Low position road lighting installations with strictly restricted upward luminous flux not only contribute to environmental conservation and prevention of glare, but also reduce veiling effects in foggy weather etc., providing higher visibility.

Under veiling effects in nighttime dense fog, sufficient roadside lighting (60 Ix) brings the effects to provide "better recognition of road alignments" and "higher visibility of a tail lamp of preceding vehicle and white lines." It is deemed appropriate that color temperature is set uniformly to 5000 $\mathrm{K}$ in view of the continuance from tunnel lighting and luminous efficiency based on the results of preliminary experiments. 
On actual expressways, however, there are local irregularities in the density of fog and in the intensity of rain and it is difficult to set and manage uniform thresholds according to a visual range and a rainfall per unit time. Therefore, it is advisable to switch from ordinary lighting to roadside lighting in line with designation of speed limit segments (50 km per hour) in foggy or rainy weather in nighttime.

In conclusion, we would like to express our sincere gratitude to Professor Toru Hagiwara, Hokkaido University for his advices and suggestions for this study.

\section{References}

CIE 023:1973. International Recommendations for Motorway Lighting.

CIE 115:2010. Recommendations for the Lighting of Roads for Motor and Pedestrian Traffic.

Illuminating Engineering Society RP-8-14:2014. Roadway Lighting

BS 5489-1:2013. Code of practice for the design of road lighting. Lighting of roads and public amenity areas

BS EN 13201-2:2015. Road lighting. Performance requirements 